\title{
Thermovision method in stress analysis of textile materials
}

\author{
by Z. Mikołajczyk ${ }^{1}$, B. Więcek ${ }^{2}$ and M. Michalak \\ ${ }_{1}^{1}$ Technical University of Łódż, Faculty of Textile Engineering, Żeromskiego 116, 90-543 Łódż, Poland

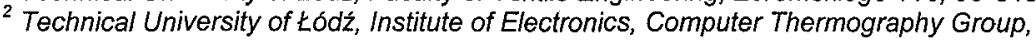 \\ 18/22 Stefanowskiego St, 90-924 Łodź, Poland, e-mail: wiecek@ck-sg.p.lodz.pl
}

\begin{abstract}
This paper presents measurements of strength of textile products with thermography monitoring. Temperature and load during elongation up to break are measured for various materials, such as yarns, woven or knitted fabrics. A correlation has been found between the temperature at the place of break and elongation and tensile strength.
\end{abstract}

\section{Introduction}

Tensile strength of linear and two-dimensional textile products belong to the parameters affecting the fabric tensile properties and its behaviour during final processing. This is why many experimental and analytical attempts were made to determine the factors affecting the tensile strength of yarns and woven or knitted fabrics.

Testing methods applied hitherto consist in stretching the textile product tested in a quasi-static, dynamic, cyclic or any other way, and in determining the load and elongation at break. These methods do not take into account phenomena occurring in the textile fabrics during stretching though knowledge of tensions and elongations during breaking is used for assessment of work done at fabric sample breaking. However, this information is not directly connected with changes occurring in the fabric during testing.

The knowledge on material strength, i.e. on destructive forces in textile fabrics, does not suffice for anticipation of undisturbed (resulting from absence of yarn/fabric breaks) run of technological processes. Dynamic process conditions occurring on knitting machines are determined with $10 \%$ allowance for the yarn strength value. Yarn breaks during processing, resulting in summing up the determined and random causes, cannot be foreseen on the base of yarn strength defined independently in laboratory tests which are not identical with real processing conditions. Apart from that, determination of conditions for undisturbed textile machinery operation would require installation of tensometric (contact) devices on every thread fed, in order to record the tension values occurring and such installation would generate disturbances in machine operation.

Thus, it is important to work out a contactless diagnostic method to observe textile material during its processing. Such a method could be obtained by application of thermovision. This paper deals with some experiments concerning a thermovision method used for testing the tensile strength of textile materials during elongation.

The thermovision method can be helpful for diagnostics of tensions in various textile materials more and more widely used for technical purposes. Presently, textile materials are used in combinations with plastics for construction elements of machinery, means of transport (e.g. aircraft wings, boat hulls, etc.). Besides, the thermovision method in tensile strength tests allows to account for anisotropic tensile properties.

Despite the increasing use of thermovision in various science branches, this method has not yet been applied in textile testing. Research carried out to date [1-3] has a diagnostic character and is not concerned with the problem assumed by the authors in this paper.

At first, some yarns and knitted fabrics were used for testing. The yarns are difficult for testing due to their irregularities - both morphological and structural, and their twist, which makes the interpretation of test results more difficult. 
For tensile testing a traditional dynamometric machine was used, whereas all observations carried out during elongation of material were not traditional. First of all, distribution of temperatures on the surface of the stretched object were observed. The sample was stretched by forces applied to the sample ends. These forces perform a work $W$ which changes the internal energy $U$ of the object tested. In case of heat exchange $Q$ with the surroundings, the formula for the work-energy exchange is given by

$$
Q+W=\Delta U
$$

Internal energy (in thermodynamical terms) is a sum of thermal motion energy of substance particles and interaction energy among the particles, and bound energy, which is a product of entropy and the thermodynamic temperature of the substance. Thus, the increase of the internal energy leads to the temperature increase. When the strength of textile material is tested, friction of fibre against fibre takes place with simultaneous fibre stretching. The friction work additionally causes some increase of surface temperature.

A direct result of oscillating motion of atoms and molecules is the infrared radiation observed with a thermovision camera. The effectiveness of a thermovision method depends on the emission factor $\varepsilon$ of the object under observation. With low $\varepsilon$, the infrared radiation power can be low when sensed by the thermovision camera detector and this makes impossible to register the temperature distribution. The emission factor depends on the type of substance and its physical parameters (temperature, humidity), on the physical parameters of the surroundings, and on the surface (lustre, colour and chemical constitution of the dyestuff).

As yet, information on infrared radiation of textile materials is scarce in the professional literature and is limited to some emission factors of materials, e.g. asbestos. In the research presented, tests were carried out on yarns and knitted fabrics made of cotton, wool, polyester, polyacrylnitril, and polyamide fibres. The emission factors $\varepsilon$ were not known for these materials and they were determined in initial tests.

\section{Testing methods}

Tests of thread groups and knitted fabrics made of the above mentioned materials were carried out on a tensile testing machine. During the whole sample testing (from the start of sample holder jaws descend till the moment of sample break) a thermovision camera monitored the distribution of surface temperature in the stretched sample.

\subsection{The thermovision camera}

We used an Inframetrics thermovision camera with 8 bits; 256 levels; $48 \mathrm{~dB}$; temperature range from $0^{\circ}$ to $1500^{\circ} \mathrm{C}$ for wave lengths $8-12 \mu \mathrm{m}$; ambient temperature from $15^{\circ}$ to $50^{\circ} \mathrm{C}$; resolution $0,05^{\circ}$; and time of registration $5 \mathrm{~ms}$. The images obtained at 13 frames per second were saved in the computer memory and then converted in an off-line system.

\subsection{Environmental conditions}

During testing, environmental conditions were kept at a constant level. In the laboratory the ambient temperature was about $+20^{\circ} \mathrm{C}$ and humidity $60 \%$.

\subsection{Emission factors $\varepsilon$}

For knitted fabrics and yarns (white colour samples) at $20^{\circ} \mathrm{C}$ we obtained for cotton fibres $\varepsilon=0.82$, wool $\varepsilon=0.83$, polyester $\varepsilon=0.93$, and polyamide $\varepsilon=0.82$. 


\subsection{Testing samples}

Tensile strength of yarns and knitted fabrics were tested. The samples of yarns were formed in skeins of preloaded parallel threads. The number of threads in the skeins was 40 , 100,200 and 400 . Samples of fabrics knitted in plain stitch were cut out as $50-\mathrm{mm}$ wide strips. The crosswise dimension of fabric sample strip and number of threads in a yarn skein sample were determined from the spatial resolution of the camera.

\section{Tests and test conditions}

The testing machine that we used was an Instron 1122 dynamometer with elongation velocity 20 and $50 \mathrm{~cm}$ per minute. At the same time the distribution of temperature on the sample surface was observed with the thermovision camera. Observations of the sample elongation, force increase and temperature distribution were performed from the moment when the jaws of the sample holder started to move until the sample break. Prior to the test, the samples were preloaded in order to straighten them. The velocity of sample elongation was determined to obtain the sample destruction time of 20 seconds which was the requirement imposed by the appropriate Polish Standard (PN). Initial distance between the sample holding jaws was $100 \mathrm{~mm}$.

\section{Thermographic observations}

The thermograms registered during testing were analysed in an off-line system. Temperature markers were placed in optional parts of the thermogram in order to obtain the temperature distribution along two optionally chosen perpendicular axes. This was used for reading the temperature values.

The temperature distribution on the sample surface was observed. Temperature range of thermograms for wool and polyacrylnitril threads was $23.05-33.0^{\circ} \mathrm{C}$ and $21.95-26.97^{\circ} \mathrm{C}$ for cotton threads. The upper limit for polyester and polyamide threads reached $70^{\circ} \mathrm{C}$. Lower temperatures were obtained for knitted fabrics. The temperature range for all knitted fabrics tested was $21.04-26.02^{\circ} \mathrm{C}$.

In the temperature distribution for all thread samples some common characteristic features were observed. The same applied to the knitted fabric samples. But a distinct difference was found when comparing the temperature distribution for threads and fabrics.

\section{Results of tests}

High values of emission factors obtained in the tests show that the substances tested are good emitters of infrared radiation. So the use of thermography was justified to observe the temperature distribution on the surfaces of the substances being tested.

Test results of tensile strength, tensile elongation, and maximum temperature increment $\Delta t$ are shown in Table 1 together with the ratios of maximum temperatures versus the breaking forces. In the column of Notes, the number of threads in samples and density (number of courses Pr and wales PK per $100 \mathrm{~mm}$ ) of fabrics are given. Three tests were made with polyamide thread samples having different number of threads in the skein.

During stretching, temperature of the fabric surface increases less than that of the skein made of the same substance. The highest temperature increase during stretching was observed for polyamide threads $\left(4.8^{\circ} \mathrm{C} / \mathrm{cN}\right)$ while we found $2.8^{\circ} \mathrm{C} / \mathrm{cN}$ for polyester threads. The lowest temperature rise was obtained for cotton threads $-0.43^{\circ} \mathrm{C} / \mathrm{cN}$. 
http://dx.doi.org/10.21611/qirt.1998.022

Table 1. Quantitative results

\begin{tabular}{|c|c|c|c|c|c|c|c|}
\hline $\begin{array}{c}\text { Test } \\
\text { Object }\end{array}$ & Fibre & $\begin{array}{c}\text { Surface mass }\left(\mathrm{g} / \mathrm{m}^{2}\right) \text { of } \\
\text { knitted fabrics and linear } \\
\text { mass of yarn skein (tex) }\end{array}$ & $\begin{array}{c}\text { Force } \\
\text { at break } \\
(\mathrm{N})\end{array}$ & $\begin{array}{c}\text { Elongation } \\
\text { at break } \\
(\%)\end{array}$ & $\begin{array}{c}\Delta t \\
\left({ }^{\circ} \mathrm{C}\right)\end{array}$ & $\begin{array}{c}\Delta \mathrm{t} / \mathrm{F} \\
\left({ }^{\circ} \mathrm{C} / \mathrm{cN}\right)\end{array}$ & Notes \\
\hline $\begin{array}{c}\text { Knitted } \\
\text { fabric }\end{array}$ & PAN & 586 & 750 & 133 & 3.56 & 0.47 & $\begin{array}{c}\mathrm{Pk} 30 \\
\mathrm{Pr} 50\end{array}$ \\
\hline $\begin{array}{c}\text { Knitted } \\
\text { fabric }\end{array}$ & Wool & 352 & 310 & 60 & 3.33 & 1.07 & $\begin{array}{c}\mathrm{Pk} 140 \\
\mathrm{Pr} 230\end{array}$ \\
\hline $\begin{array}{c}\text { Knitted } \\
\text { fabric }\end{array}$ & PA & 98 & 180 & 30 & $>4.98$ & 2.77 & $\begin{array}{c}\mathrm{Pk} 80 \\
\mathrm{Pr} 60\end{array}$ \\
\hline $\begin{array}{c}\text { Knitted } \\
\text { fabric }\end{array}$ & PE & 109 & 405 & 80 & 3.77 & 0.93 & $\begin{array}{c}\mathrm{Pk} 140 \\
\mathrm{Pr} 90\end{array}$ \\
\hline $\begin{array}{c}\text { Knitted } \\
\text { fabric }\end{array}$ & Cotton & 240 & 395 & 75 & 3.92 & 0.99 & $\begin{array}{c}\mathrm{Pk} 140 \\
\mathrm{Pr} 90\end{array}$ \\
\hline $\begin{array}{c}\text { Knitted } \\
\text { fabric }\end{array}$ & Cotton & 240 & 1150 & 41.7 & 32.43 & 2.8 & 40 threads \\
\hline Yarn & PE & 5000 & 620 & 31.7 & 4.37 & 0.7 & 100 threads \\
\hline Yarn & PAN & 13200 & 640 & 25.1 & 6.73 & 1.05 & 100 threads \\
\hline Yarn & Wool & 7000 & 1060 & 34.2 & 4.54 & 0.43 & 400 threads \\
\hline Yarn & Cotton & 8000 & 1300 & 20.8 & 33.04 & 2.5 & 200 threads \\
\hline Yarn & PA & 4000 & 1270 & 23.3 & 43.45 & 3.4 & 200 threads \\
\hline Yarn & PA & 4000 & 610 & 18.7 & 29.29 & 4.8 & 100 threads \\
\hline Yarn & PA & 2000 & & & & \\
\hline
\end{tabular}

These factors for polyester knitted fabrics were almost as high as for the polyester yarns $\left(2.77^{\circ} \mathrm{C} / \mathrm{cN}\right)$, while the lowest values were obtained for polyacrylnitril knitted fabrics $\left(\Delta t / \Delta F=0.47^{\circ} \mathrm{C} / \mathrm{cN}\right)$.

Fig. 1 shows for polyester yarns thermograms in the initial, central, and final phases of elongation. Obviously the surface temperature of the sample increases during stretching; the temperature distribution is not uniform. The second and third thermograms indicate that the temperature of the whole sample decreases after reaching the maximum and that the break occurs in the region where the lower temperature was observed during all the time of stretching. Temperature markers were placed on thermograms for illustration.

Changes in temperature distribution during sample stretching, registered on thermograms, allow for the following conclusions:

- surface temperature increases at the beginning of sample stretching;

- surface temperature distribution is not uniform; a thermal gradient is observed during stretching of the sample whereas the gradient value and its mathematical sign are subject of changes during the whole stretching process;

- average sample temperature increases and reaches its peak for samples tested in form of yarn skeins; while such peaks were not observed on knitted fabrics;

- range of temperature changes was different for each type of sample; in general, the range embraces $10^{\circ} \mathrm{C}$, but for the polyester yarns the difference range runs to $50^{\circ} \mathrm{C}$;

- skein temperature decreases after the sample break; in case of knitted fabrics, on the other hand, the temperature increases in the region of destruction;

- yarn sample break in regions of lowest temperatures while the fabric samples break in regions of highest temperatures. In yarn samples, the region of break is located in the middle of the sample whereas the fabric sample breaks at the sample holding jaws. 
http://dx.doi.org/10.21611/qirt.1998.022

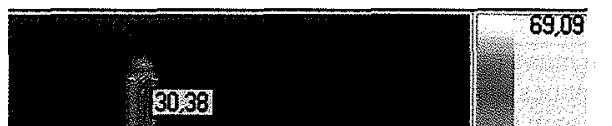

58,28

46.94

33,94

3083

$\overline{6909}$

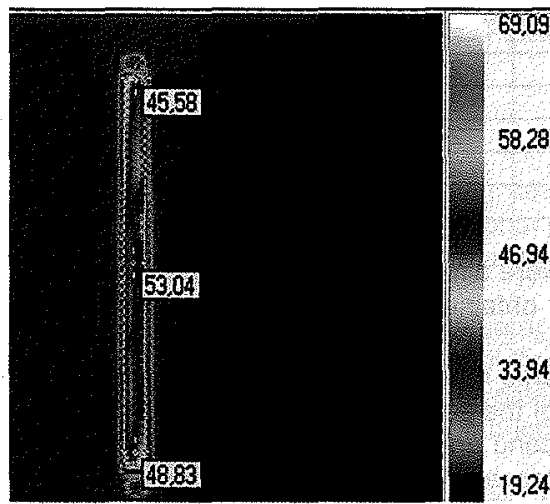

6909

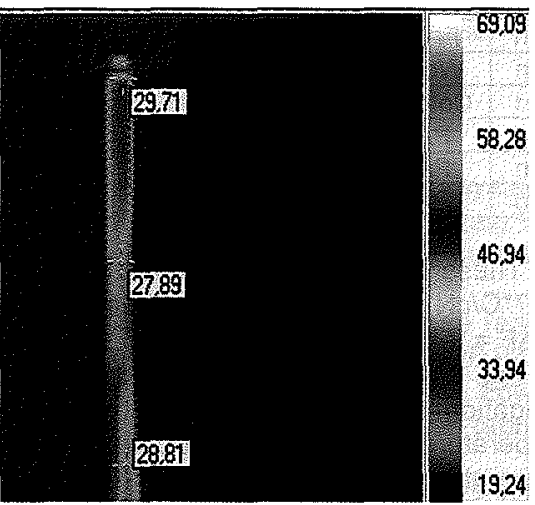

Fig. 1. Thermograms registered during initial, central, and final phase of stretching the polyester yarn

The results of observations are graphically presented. E.g., in Fig. 2 relationships of average sample temperature increment of polyacrylnitril yarn are shown versus elongation, and Fig. 3 shows an appropriate graph for a polyacrylnitril fabric. These graphs are characteristic for all samples tested.

The temperature of yarn samples increases at the beginning of stretching, and then it decreases, whereas for the fabric samples the temperature increases until the break without showing any peaks.

Besides, we analysed the relationships between the temperature in the place of break of the sample tested, specific tensile strength $P$, and sample elongation $\Delta l$. The graphs $T=f(P)$ and $T=f(\Delta l)$ were produced for yarn samples made of skeins and of knitted fabrics.

Fig. 4 shows a graph $T=f(P)$ for a PAN knitted fabric. Similar relationships were obtained for all yarn and fabric samples mentioned above. 
http://dx.doi.org/10.21611/qirt.1998.022

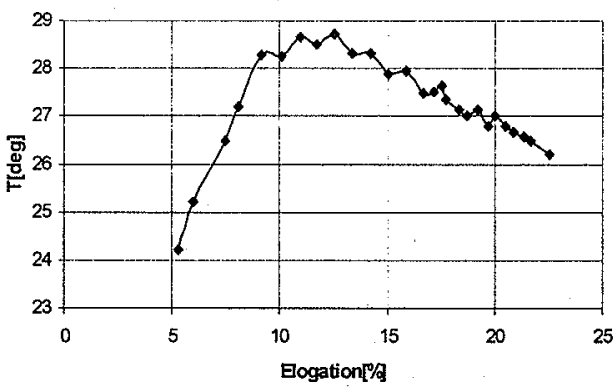

Fig. 2. Polyacrylnitril yarn; relationship between average temperature in-crement and elongation

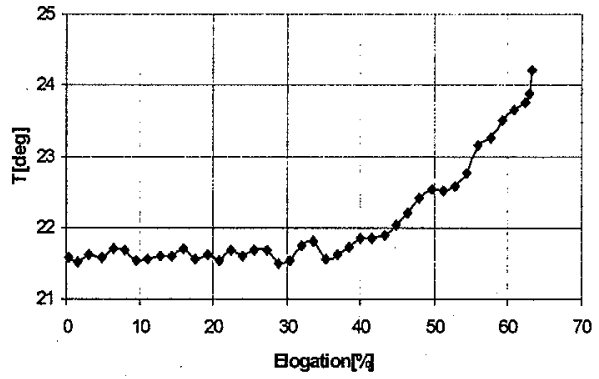

Fig. 3. Polyacrylnitril knitted fabric; relationship between average temperature in-crement and elongation

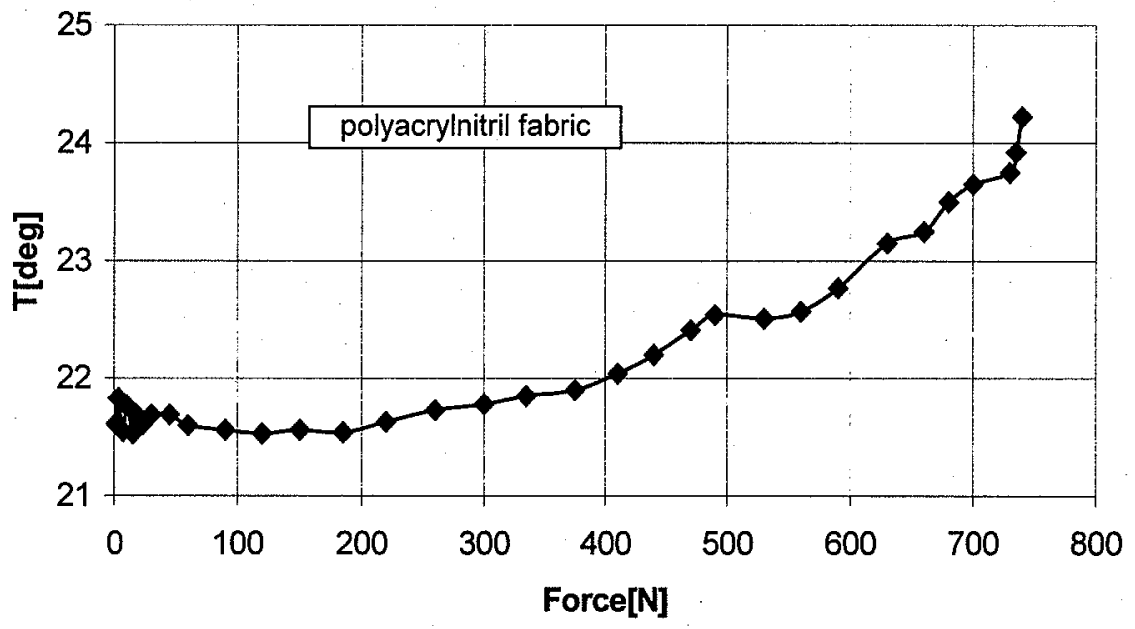

Fig. 4. Relation between increment of average temperature and load increment

\section{Discussion of test results}

The results show that the temperature of the tested sample increases with the sample load. There is some correlation between the temperature at the place of break and elongation, and tensile strength of the sample. Some types of fibres emit a relatively strong infrared radiation during stretching.

Temperatures over $40^{\circ} \mathrm{C}$ were observed on thermograms for polyamide yarns. Unfortunately, it is not yet possible to determine the actual temperature; the results obtained are just some indicators of the infrared radiation output.

The results obtained show that the methods hitherto used for testing the tensile strength of textile products are imperfect. They are focussed on the determination of boundary values of material destruction and do not account for processes that occur during building-up of stresses. The results of sample surface temperature obtained in this work show the potential of information on the behaviour of threads in textile manufacturing processes, to foresee the eventual process disturbances caused by the destruction of threads, and to eliminate the causes. 
Results of tests performed on sets of threads, i.e. on yarn skeins, can be used for modelling the tensile strength of a single thread. Of course, the results obtained till now can only be used for filament yarns. We also should mention some elements, which affect the accuracy of measurements presented in this paper:

- timing of registration the thermovision image with sample elongation was not solved to full satisfaction;

- thermovision image physically changes during sample stretching; dimensions and distribution of stresses are not uniform in the sample, single threads do not break in unison;

- thermograms show emission of infrared radiation from both the surface and the inside of the sample; thus, the thermovision image does not equally feature the temperature of the whole sample; at the sample edge, the infrared radiation is emitted only from the sample surface whereas in the central part of the sample the infrared radiation is generated by both the surface and the inside of the sample.

It follows that assessment of the energy phenomena in textile materials during tensile testing is an awkward problem. Nevertheless, initial steps must be taken in order to use the thermovision method for this kind of examinations and to try to analyse the course of technological processes in the manufacture of textile products. The course of elongation must be considered as an aspect of thermodynamics in order to determine the relationship between the temperature rise and the stresses in the knitted fabrics.

According to Zurkov's thermodynamic theory of material strength, the strength of a single fibre is a function of molecular and supermolecular structure parameters, as well as a function of dynamic parameters (tensile stresses) and thermal state of the fibre. It follows from the first and second principle of thermodynamics that the work of fibre deformation changes into an increment of free energy. Free energy, in turn, is a difference between the internal energy being a sum of energy of all intra- and intermolecular bonds in fibre substance, and the energy determined by the value of entropy and temperature of the substance. Work carried out on a fibre during stretching leads to its internal energy increase, and - what follows - to the infrared radiation. Interpretation of results obtained in textile testing is difficult because of the random distribution of the physical and mechanical properties tested.

\section{REFERENCES}

[1] WIĘŹLAK (W.), ZIELIŃSKI (I.) - Clothing heated with textile heating elements; international journal of clothing science and technology; 1993, pp. 9-23.

[2] MICHALAK (M.), STASIAK (M.) - Cieplne zjawiska w przędzeniu, jako nowe źródło informacji o procesie (Thermal phenomena in spinning as a new source of information on spinning process). Przegląd Wókienniczy, 1991, pp.189-192. (in Polish)

[3] MIKOKAJCZYK (Z.) - Metoda termowizyjna w diagnostyce procesów technologicznych dziania (Thermovision method in stress diagnosis of technological process in knitting), III Intenational Conference on "Modern environment-friendly techniques and technologies in knitting", Ustroń, 24-26.06.1998. (in Polish) 